\title{
Clinicians' justification of imaging: do radiation issues play a role?
}

\author{
Lars Borgen • Erling Stranden • Ansgar Espeland
}

Received: 9 December 2009 /Revised: 21 January 2010/Accepted: 25 January 2010/Published online: 23 June 2010

(C) European Society of Radiology 2010

\begin{abstract}
Objective To explore clinicians' knowledge and consideration of radiation, in relation to their referral practice and use of referral guidelines for imaging.

Methods A questionnaire was handed out to 213 clinicians in Norway; all responded: 77 general practitioners, 71 hospital physicians and 65 non-physicians (55 manual physiotherapists, 10 chiropractors). Questions concerned weighting of radiation dose, guideline use, referrals unlikely to affect treatment, doses from imaging procedures, ranking of imaging as radiation source, and deterministic and stochastic effects. For radiation knowledge, a total score was aggregated.

Results The mean radiation knowledge score was 30.4/71. Most respondents underestimated doses from high-dose imaging, e.g., barium enema (94.7\%), chest CT (57.7\%) and abdominal CT (52.7\%). Limited radiation knowledge was not compensated by using guidelines. Only $20 \%$ of physicians and $72 \%$ of non-physicians used referral guidelines. Non-physicians weighted radiation dose as being more important than physicians when referring; they also
\end{abstract}

L. Borgen $(\bowtie) \cdot$ E. Stranden

Department of Radiology, Buskerud Hospital,

Dronning gaten 28,

3004 Drammen, Norway

e-mail: lars.borgen@sb-hf.no

L. Borgen $\cdot$ E. Stranden

Faculty of Health, Buskerud University College,

P.O. Box 753, 3007 Drammen, Norway

A. Espeland

Department of Radiology, Haukeland University Hospital,

5021 Bergen, Norway

A. Espeland

Department of Surgical Sciences, University of Bergen,

5021 Bergen, Norway reported fewer referrals as being unlikely to affect treatment. Such referrals and not using guidelines were related to lower weighting of radiation dose but not to radiation knowledge.

Conclusion Limited radiation knowledge and guideline use indicate suboptimal justification of referrals. When justifying imaging, weighting of radiation dose may play a larger role than detailed radiation knowledge.

Keywords Diagnostic imaging - Referral guidelines · Radiation dosage $\cdot$ Questionnaires $\cdot$ Radiation protection

\section{Introduction}

The increasing volume of medical imaging and particularly multislice computed tomography (CT) during the last few decades has turned radiation protection into one of the main concerns of the radiological community [1-4]. Justification and optimisation are cornerstones of radiation protection $[5,6]$, and this report deals with justification.

To be able to justify a radiation-based medical imaging procedure - that is, to weigh its costs against its benefits [6] the referring clinician needs to know the magnitude of the radiation dose given and the possible detrimental effects of this exposure. To some degree, the lack of such knowledge could be compensated for by using referral guidelines [7-9] in the justification process.

Former studies have revealed that referring physicians possess limited knowledge about ionising radiation and its carcinogenic potential [10-22], and that referral guidelines are not widely used [23-26]. However, we have little data on radiation knowledge and use of referral guidelines among referring non-physicians, e.g., chiropractors [27, 28]. We also lack data on how knowledge and attitudes about radiation 
Table 1 Questions about medical radiation use and radiation protection

Questions

To what extent are the listed factors

important when you refer a patient for imaging?

Radiation dose to patient

Patient's wish

Impact on diagnosis

Impact on treatment

Impact on patient's future health

Do you know of imaging referral guidelines where referrers can seek information on which investigations are indicated for which conditions?

Have you ever used such referral guidelines?

Do you refer patients for imaging in cases when you consider it most unlikely that the imaging results will affect treatment of the patient?

If yes, what is the proportion of such referrals among all your referrals (circa)?

What are the reasons why you may refer when the imaging results most likely will not affect treatment?

Please weight the listed reasons

Patient expectations

Give the patient the feeling of being taken seriously

Lack of time, "get the patient out of the office", discharge the patient

Expectations from relatives

Compensate for insufficient clinical examination

Normal findings will reassure the patient

Please estimate the effective dose of the listed imaging procedures, compared to a chest $\mathrm{x}$-ray (front and side projection). Please put a mark, even if you are uncertain ${ }^{\mathrm{a}}$ Cerebral CT

Pelvic radiography

Cerebral MRI

Intravenous pyelography

Chest CT

Barium meal fluoroscopy

Barium enema

Abdominal CT

Kidney ultrasound

Thoracic spine radiography

Sinus $\mathrm{x}$-ray

Sinus CT

We ask you to rank the contributors to the mean effective radiation dose for a Norwegian in 2006 Medical imaging

Radon in homes

Background gamma radiation

Pollution from Sellafield in England

Pollution from the Chernobyl nuclear plant accident

Detrimental effects of radiation are divided into deterministic and stochastic effects. Are you familiar with these terms? If yes, go to next question
Response categories

Weighting of importance $1-6 ; 1=$ very important, $6=$ not important

Yes/no

Yes/no

Yes/no

$1 \%, 5 \%, 10 \%, 20 \%, 50 \%$

Weighting of importance $1-4 ; 1=$ very important, $4=$ not important

Corresponding numbers of chest $\mathrm{x}$-rays (front and side projection): $0-1,1-10,10-50,50-200$

Rank, $1=$ largest contributor, $5=$ smallest contributor 
Table 1 (continued)

\begin{tabular}{ll}
\hline Questions & Response categories \\
\hline This is a list of potential detrimental effects of radiation. & Stochastic/deterministic \\
Please mark whether you think these effects are stochastic & \\
or deterministic (one mark per effect) & \\
Leukaemia & \\
Infertility & \\
Foetus abnormalities & \\
Genetic adverse effects & \\
Cataract & \\
Lung cancer
\end{tabular}

${ }^{a}$ Estimates of effective dose were compared with national reference values or — when such values were lacking — with doses measured at the first author's department

issues may relate to referral practice. Further data could help to design strategies for improving different clinicians' justification processes and referral practices.

Accordingly, we explored general practitioners', hospital physicians' and non-physicians' (1) radiation knowledge, (2) weighting of radiation dose when referring, (3) use of referral guidelines, (4) rate of and reasons for referrals unlikely to affect treatment, and (5) if this rate and their guideline use is related to their radiation knowledge and weighting. We hypothesised that clinicians who put less emphasis on radiation issues order imaging unlikely to affect treatment more often and use referral guidelines less often.

\section{Materials and methods}

In this study from Norway, hospital physicians, general practitioners, manual physiotherapists and chiropractors filled in an anonymous questionnaire. Manual physiotherapists acquired a referral licence for all techniques in 2006

Table 2 Total radiation knowledge score by respondent group

\begin{tabular}{llll}
\hline & $\mathrm{N}$ & Mean score & $\mathrm{SD}$ \\
\hline General practitioners & 77 & 31.0 & 8.4 \\
Hospital physicians & 71 & 32.3 & 9.4 \\
Surgeons & 13 & 34.2 & 10.3 \\
Internists & 19 & 37.0 & 11.6 \\
Neurologists & 10 & 24.9 & 4.6 \\
Orthopaedics & 12 & 31.4 & 5.3 \\
Paediatricians & 13 & 30.9 & 8.4 \\
Rheumatologists & 4 & 29.5 & 5.2 \\
Non-physicians & 65 & 27.7 & 6.7 \\
$\quad$ Manual physiotherapists & 55 & 27.3 & 6.4 \\
Chiropractors & 10 & 30.3 & 8.4 \\
\hline
\end{tabular}

Mean score was significantly different among general practitioners, hospital physicians and non-physicians: $\mathrm{p}=0.03$, multiple linear regression analysis and chiropractors in 1991 [29]. The study did not require approval from a research ethics committee.

Our questionnaire was based on literature review, a pilot study of six respondents and individual interviews with four clinicians to test face validity. It was handed out to 71 hospital physicians at all grades during their morning meetings at a 500-bed general hospital and to 77 general practitioners, 55 manual physiotherapists and 10 chiropractors during lectures at nation- or countywide courses of general interest within their fields, not related to radiation issues. All clinicians attending the actual meetings/ lectures were asked to fill in the questionnaire, which took about 15 min. They were not informed about the questionnaire session in advance. The first author supervised this session to ensure unaided answers.

The questions concerned, in this order: respondents' age and gender, their weighting of (six-point scale) radiation dose and four other factors (Table 1) when referring for imaging, whether they knew of (yes/no) and had used (yes/ no) referral guidelines, if they referred for imaging that most unlikely would affect treatment (yes/no), their approximate rate of such referrals $(1,5,10,20$ or $50 \%)$ and the importance of (four-point scale) six listed reasons for such referrals (Table 1).

The next question was about effective dose, in number of chest $\mathrm{x}$-rays $(0-1,1-10,10-50$ or $50-200)$ from 12 imaging procedures including radiography, fluoroscopy, $\mathrm{CT}$, magnetic resonance imaging (MRI) and ultrasound [30] (Table 1). Respondents then had to rank the contribution of medical imaging to the mean effective dose for a Norwegian, compared with that of radon in homes, background gamma radiation, pollution from Sellafield in England and food pollution from the Chernobyl nuclear plant accident [31]. Finally, respondents were asked if they knew the terms deterministic and stochastic effects; if so, they should categorise six effects as either deterministic or stochastic [5].

We constructed a total radiation knowledge score ranging from 0 to 71 . For the 12 imaging procedures, a 
correct dose gave 3 points and the closest wrong dose 1 point, yielding a maximum of 36 points. Ranking of radiation sources gave a maximum of 18 points. Ranking radon first and imaging second gave 9 points each, and the closest wrong rank gave 4 points. Knowing the terms stochastic and deterministic gave 5 points, and categorising the six detrimental effects correctly gave 2 points each, resulting in a maximum of 17 points. Missing data gave 0 points, and a total radiation knowledge score was noted for all participants.

For continuous normal distributed data, we used Student's t-test and for categorical data, Wilcoxon signed rank test, Kruskal-Wallis, Mann-Whitney, Friedman's and chi-squared tests, and Spearman's rho, as appropriate (see Results). Multiple linear regression analysis was used to examine factors that could influence radiation knowledge. Data were analysed using SPSS (version 16, SPSS Inc., Chicago, IL). A two-tailed $\mathrm{p}<0.05$ was accepted as statistically significant.

\section{Results}

All invited clinicians $(n=213)$ participated in the study. Their mean age (range) was 44.6 (26-73) years. There was a male predominance $(66 \%-75 \%)$ within all three main respondent groups (77 general practitioners, 71 hospital physicians and 65 non-physicians).

\section{Radiation knowledge}

The total score of radiation knowledge was mean 30.4 (SD 8.5 ) or $42.8 \%$ of the maximum. Analysed with a multiple linear regression analysis, total score did not correlate with age, but differed between men and women (mean 31.4 vs. 28.2, $\mathrm{p}=0.01$ ) and among the three main respondent groups $(p=0.03$, Table 2). Age, sex and group explained only $6.4 \%$ of the variation in this score $\left(\mathrm{R}^{2}=0.064\right)$.

Most respondents underestimated radiation doses from high dose imaging: for barium enema $94.7 \%$, barium meal $68.3 \%$, chest CT $57.6 \%$, intravenous pyelography $55.1 \%$ and abdominal CT $52.7 \%$ (Fig. 1a). The dose from paranasal sinus CT (Fig. 1b) was overestimated by $94.8 \%$. For thoracic spine and pelvic radiography (Fig. 1c), similar proportions underestimated $(21.6 \%, 18.7 \%)$ and overestimated dose $(19.7 \%, 19.1 \%)$. According to $10.5 \%$ and $4.8 \%$ of respondents, MRI and ultrasound, respectively, implied some radiation dose. Dose estimates were given by 205-208 (96\%-98\%) of the 213 participants.

When ranking the magnitude of five different radiation sources for an average Norwegian, 38 (18.2\%) out of 209 respondents correctly ranked medical imaging $(1.1 \mathrm{mSv} / \mathrm{year})$
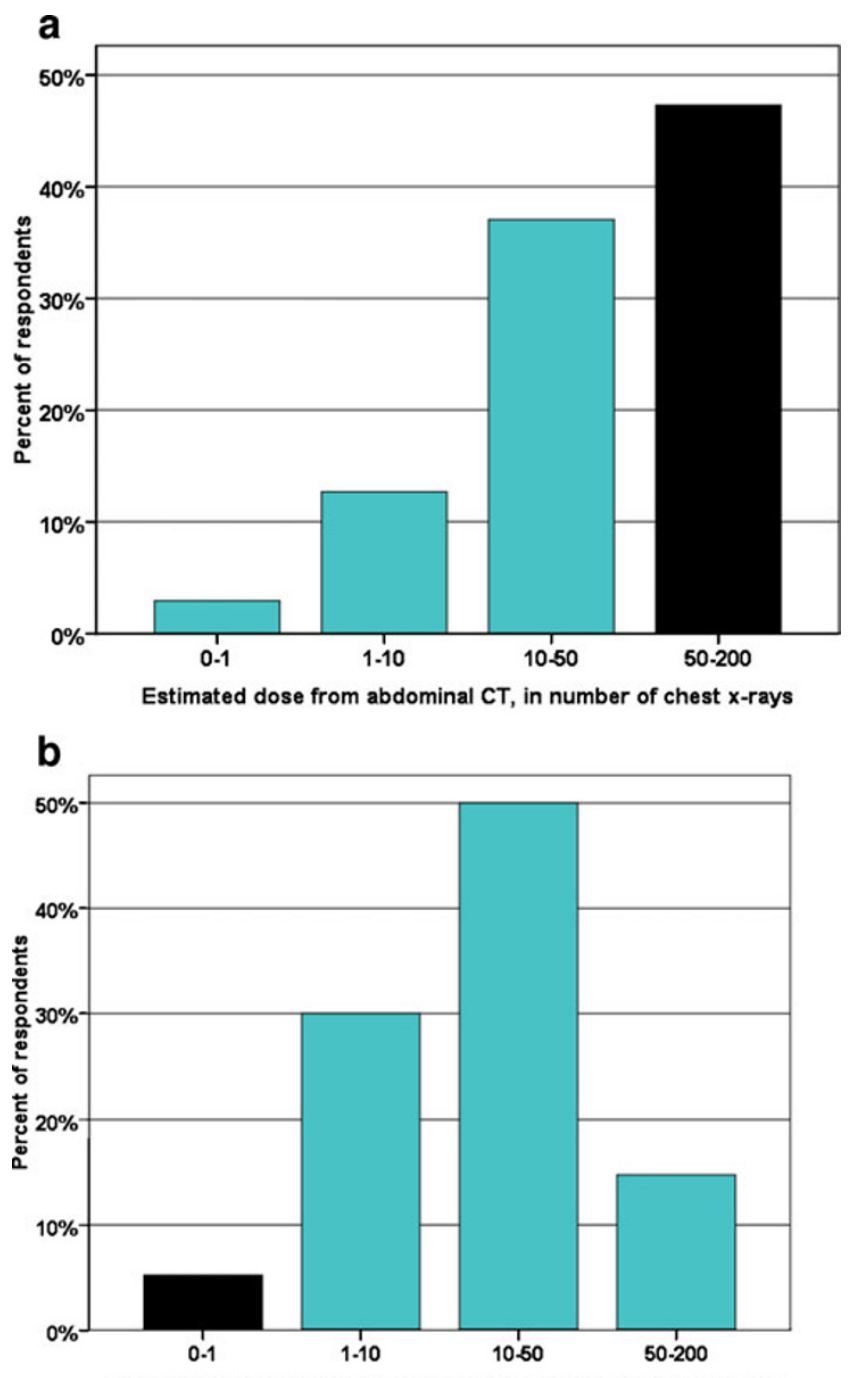

Estimated dose from paranasal sinus $\mathrm{CT}$, in number of chest $\mathrm{x}$-rays

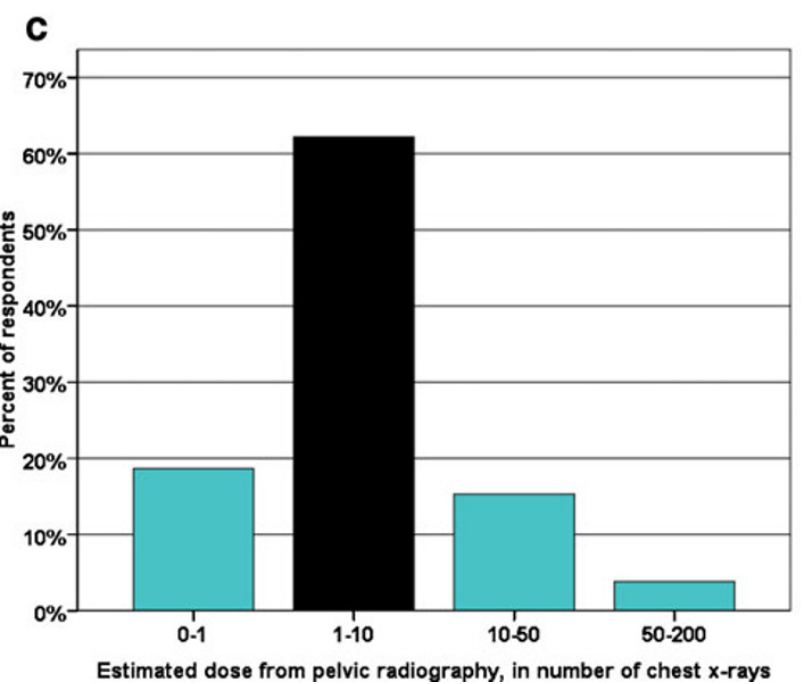

Fig. 1 Distribution of respondents according to their radiation dose estimates in number of chest x-rays for abdominal CT (a), paranasal sinus CT (b) and pelvic radiography (c). Correct answers are marked in black 
Table 3 Median score (interquartile range) for weighting the importance of different factors when referring for imaging: $1=$ very important, $6=$ not important

\begin{tabular}{llllll}
\hline & $\begin{array}{l}\text { Radiation } \\
\text { dose }\end{array}$ & $\begin{array}{l}\text { Patient's } \\
\text { wish }\end{array}$ & $\begin{array}{l}\text { Impact of imaging } \\
\text { on diagnosis }\end{array}$ & $\begin{array}{l}\text { Impact of imaging } \\
\text { on treatment }\end{array}$ & $\begin{array}{l}\text { Impact of imaging } \\
\text { on future health }\end{array}$ \\
\hline General practitioners $(\mathrm{n}=77)$ & $3.0(2.0)$ & $4.0(3.0)$ & $1.0(1.0)$ & $1.0(0.0)$ & $1.0(1.0)$ \\
Hospital physicians $(\mathrm{n}=70)$ & $3.0(1.0)$ & $4.0(2.0)$ & $1.0(1.0)$ & $1.0(0.0)$ & $1.0(1.0)$ \\
Non-physicians $(\mathrm{n}=65)$ & $2.0(2.0)$ & $5.0(1.0)$ & $1.0(1.0)$ & $1.0(1.0)$ & $1.0(1.0)$ \\
Total (n=212) & $2.5(1.0)$ & $4.0(2.0)$ & $1.0(1.0)$ & & $1.0(1.0)$ \\
\hline
\end{tabular}

as second after radon (3.0 mSv/year); 72 (34.4\%) ranked imaging too high and $99(47.4 \%)$ too low.

Only $34(16.7 \%)$ out of 204 respondents stated they knew the terms deterministic and stochastic effects. When categorising six different detrimental effects as either stochastic or deterministic, these 34 respondents' mean score was 6.8/12; chance would yield 6/12.

Weighting of radiation dose when referring

Considering a referral for imaging, respondents in the total sample weighted radiation dose as more important than the patient's wish ( $\mathrm{p}<0.001$, Wilcoxon signed rank test), but less important than the impact of the imaging on the patient's diagnosis, treatment or future health $(\mathrm{p}<0.001$, Friedman's test) (Table 3). Non-physicians rated radiation dose as more important than did general practitioners $(p<0.001$, Mann-Whitney test) and hospital physicians $(\mathrm{p}=0.001$, Mann-Whitney test). Complete ratings were given by 212 $(99.5 \%)$ of the respondents.

\section{Use of referral guidelines}

Only $58.0 \%(123 / 212)$ reported that they knew of referral guidelines, and $35.7 \%$ (76/213) had made use of such guidelines. The proportion that had used guidelines was higher for non-physicians $(72.3 \%)$ than for general practitioners (19.5\%) and hospital physicians $(19.7 \%)(\mathrm{p}<0.001$, chi-squared tests).

\section{Referrals unlikely to affect treatment}

As many as $88.3 \%$ of the general practitioners, $83.1 \%$ of the hospital physicians and $56.9 \%$ of the non-physicians referred for imaging that would be most unlikely to affect treatment ( $\mathrm{p}<0.001$, chi-squared test). General practitioners reported a higher percentage of such referrals (median 10\%) than did hospital physicians $(5 \%, \mathrm{p}=0.04$, chi-squared test) and non-physicians $(5 \%, \mathrm{p}<0.001$, chi-squared test).

Compared with the other four listed reasons for referrals that hardly affect treatment (Table 1), "normal findings will reassure the patient" and to "give the patient the feeling of being taking seriously" were rated as more important $(p<0.001$, Friedman's test). "Patient expectations" was rated as more important by general practitioners than by hospital physicians and non-physicians $(p<0.001$, Mann-Whitney test). Non-physicians rated "lack of time", "expectations from relatives" and to "compensate for insufficient clinical examination" as less important reasons than general practitioners and hospital physicians $(\mathrm{p}<0.001$, Mann-Whitney test).

Radiation issues in relation to referrals and guideline use

Lower weighting of radiation dose was related to admitting referrals unlikely to affect treatment (Figs. 2 and 3) and not having used guidelines (Fig. 4). However, the total radiation knowledge score was similar for clinicians denying $(\mathrm{n}=49)$ and admitting $(\mathrm{n}=164)$ referrals unlikely to affect treatment (mean 28.7 vs. $31.0, p=0.10$, Student's ttest), did not correlate with their rate of such referrals $(r=0.14, p=0.85$, Spearman rho), and was similar for those

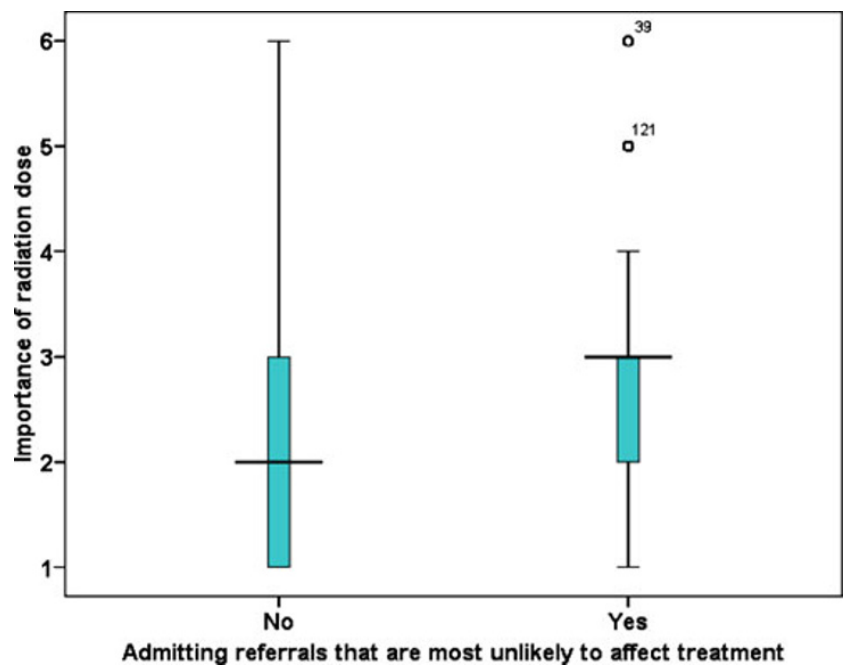

Fig. 2 Weighting the importance of radiation dose in relation to admitting referrals that are most unlikely to affect treatment $(\mathrm{r}=0.14$, $\mathrm{p}=0.037$, Spearman rho). 1 = very important, $6=$ not important. Boxand-whisker plot where the grey box represents the interquartile range, the middle horizontal line the median and the whiskers the range. Numbered points are outliers 


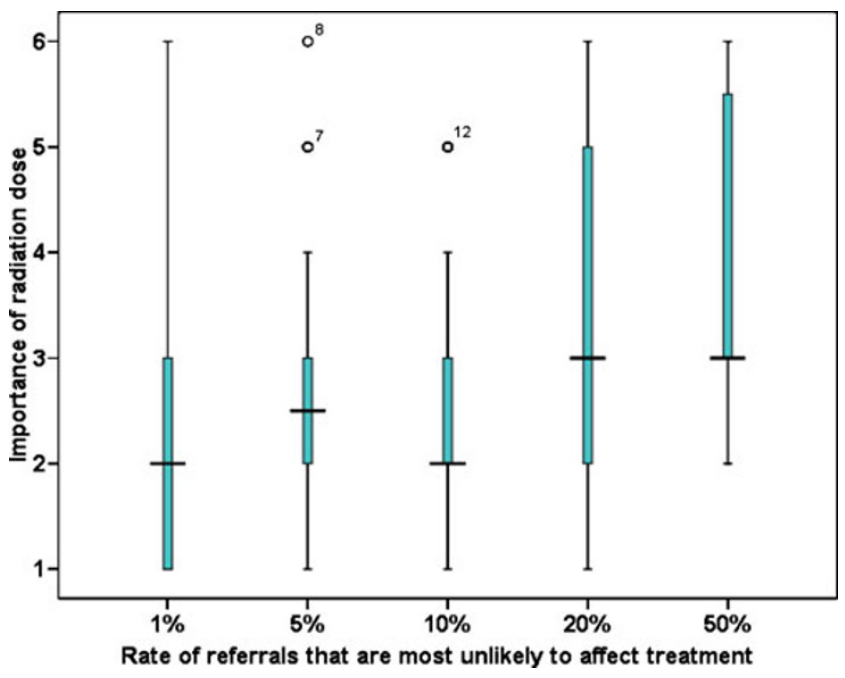

Fig. 3 Weighting the importance of radiation dose in relation to percentage of referrals being most unlikely to affect treatment $(\mathrm{r}=0.21$, $\mathrm{p}=0.005$, Spearman rho). $1=$ very important, $6=$ not important. Boxand-whisker plot where the grey box represents the interquartile range, the middle horizontal line the median and the whiskers the range. Numbered points are outliers

who had and those who had not used guidelines (mean 29.4 vs. $31.0, \mathrm{p}=0.18$, Student's t-test).

\section{Discussion}

In this study, all three respondent groups possessed limited radiation knowledge, and $80 \%$ of the physicians did not use referral guidelines. Respondents who weighted radiation dose lower when referring reported less guideline use and

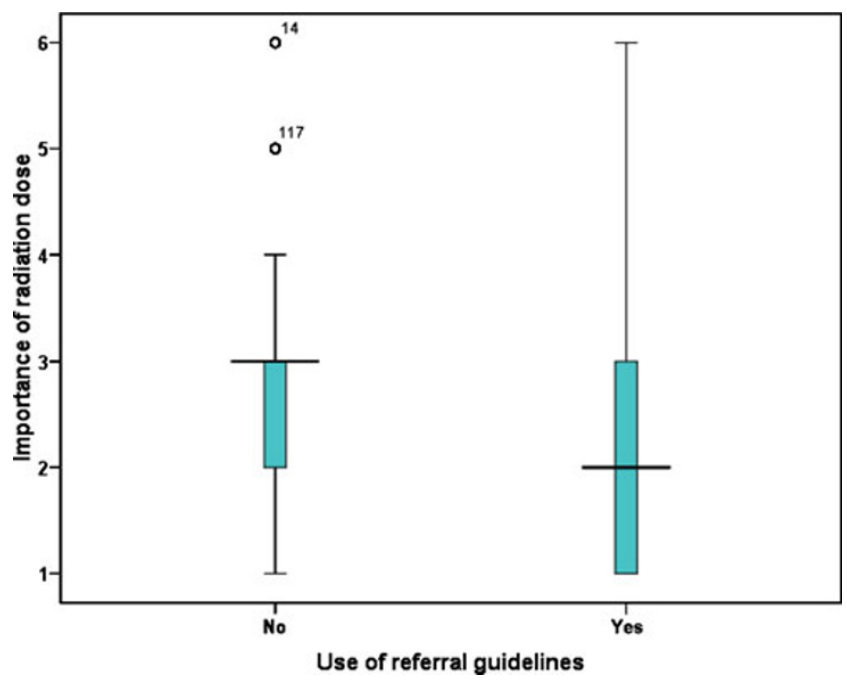

Fig. 4 Weighting the importance of radiation dose in relation to using referral guidelines $(r=0.18, p=0.009$, Spearman rho). $1=$ very important, $6=$ not important. Box-and-whisker plot where the grey box represents the interquartile range, the middle horizontal line the median and the whiskers the range. Numbered points are outliers more referrals as being unlikely to affect treatment. Nonphysicians reported fewer such referrals, more use of referral guidelines and more weight on radiation dose.

Strengths and limitations

A $100 \%$ participation rate and the unprepared, unaided responses to our questionnaire yielded more valid data on radiation knowledge than achievable in a postal or e-mail survey. However, the use of questionnaires has inherent limitations, as some answers reflect respondents' subjective opinions. In the present study, respondents' self report on their own practice should be interpreted with care, e.g., it may be biased by a wish to answer "correctly". Such bias was reduced by avoiding respondent identifiers on the questionnaire and hardly explains the most salient differences and relations.

Since responses had to be unprepared and supervised, it was not feasible to recruit respondents randomly from their respective professional groups to achieve a representative sample. Our respondents may nevertheless be fairly comparable to their groups on a national level. Mean age in the study sample vs. the national population was 48.1 vs. 46.8 years for general practitioners and 40.0 vs. 43.3 years for hospital physicians [32]. Hospital physicians were recruited at morning meetings for all residents, junior and senior physicians at a general hospital with common subspecialties (Table 2). General practitioners and non-physicians were recruited from courses of general interest.

\section{Discussion of findings}

Our study confirmed that clinicians often underestimate radiation doses [10-22]. However, clinicians overestimated doses too, and some even reported radiation from MRI and ultrasound, as has also been found in other studies [10-12, $17,19,22]$. Similarly, physicians in a former study overestimated the teratogenic risk from ionising imaging [33]. Thus, balanced information on radiation doses and risks seems mandatory.

Despite their slightly poorer radiation knowledge, nonphysicians put more weight on radiation dose when referring. One reason for this may be that non-physicians face mostly benign conditions, where radiation dose is more relevant than in cases of for example malignancy. A less likely reason, but one that we cannot rule out, is that some manual physiotherapists may have rated radiation dose higher to show that they deserve their recently acquired referral licence.

Although concurring with previous findings [24, 25, 34], it was remarkable that only $20 \%$ of the physicians had used referral guidelines. Clearly, few physicians used the 
Norwegian translation of the EU Commission Guidelines available on the web [35]. The much higher proportion (72\%) of non-physicians using guidelines could be partly explained by the fact that the manual physiotherapists have developed their own guidelines [36] and that sub-specialists may be more familiar with their own adapted guidelines than with general guidelines on the same topic [26]. More use of referral guidelines among manual physiotherapists may also be partly due to their relatively short experience with imaging referrals.

Respondents' rates of referrals unlikely to affect treatment were smaller than some reported rates of unjustified imaging (5-10\% vs. 20\%) [37-39]. Our respondents may have underestimated their own rates, but the rate of unjustified and/or treatment-irrelevant imaging in Norway is not known.

As limited radiation knowledge was not compensated for by using referral guidelines, relevant information may have lacked in the justification process. Our study was not designed to examine the effect of efforts to improve this process. Yet, a higher weighting of radiation dose when referring was related to more guideline use and fewer referrals regarded as being unlikely to affect treatment. We therefore believe that increased weighting of radiation dose can help to optimise referral practice.

\section{Implications and conclusions}

Our findings do not necessarily apply in other health care systems, and they need confirmation in further studies. Nonetheless, these results have implications that may be of value to those attempting to improve the justification of imaging in cooperation with clinicians.

First, referring clinicians, both non-physicians and physicians, need information about radiation protection and the detrimental effects of radiation. To prevent overuse as well as underuse of medical imaging, this information must be balanced.

Second, referral guidelines should be more actively distributed and implemented [40-42]. For example, as a start, one could incorporate such guidelines into every hospital's computerised referral system, giving real-time, easily accessible decision support for referring clinicians [24, 42-46].

Third, interventions to improve referral practice should target clinicians' attitudes and not only their knowledge. Clinicians' weighting of radiation dose seems more important to their referral practice than their detailed radiation knowledge.

Fourth, different interventions may be required for nonphysicians and physicians, as they may differ in their attitudes towards radiation issues and in pre-existing guideline use and referral practice.
In conclusion, scarce radiation knowledge and limited use of referral guidelines indicate that the process of justifying imaging referrals needs to be improved. In this process, weighting of radiation dose played a larger role than detailed radiation knowledge. We found support for the hypothesis that clinicians who put less weight on radiation issues order imaging unlikely to affect treatment more often and use referral guidelines less often. Non-physicians used guidelines more often than physicians and weighted radiation dose as being more important. Efforts to improve the justification of radiation-based medical imaging should nevertheless raise awareness of radiation protection issues among all groups of referring clinicians.

Acknowledgements We would like to thank Are Hugo Pripp, PhD, Biostatistics Unit, Research Services Department, Oslo University Hospital, Oslo, for his assistance with statistical issues.

\section{References}

1. Borretzen I, Lysdahl KB, Olerud HM (2007) Diagnostic radiology in Norway trends in examination frequency and collective effective dose. Radiat Prot Dosim 124:339-347

2. Brenner DJ, Hall EJ (2007) Computed tomography-an increasing source of radiation exposure. N Engl J Med 357:2277-2284

3. Fazel R, Krumholz HM, Wang Y, Ross JS, Chen J, Ting HH, Shah ND, Nasir K, Einstein AJ, Nallamothu BK (2009) Exposure to low-dose ionizing radiation from medical imaging procedures. $\mathrm{N}$ Engl J Med 361:849-857

4. Lauer MS (2009) Elements of danger-the case of medical imaging. N Engl J Med 361:841-843

5. The International Commission on Radiological Protection (2007) Recommendations of the International Commission on Radiological Protection. ICRP publication 103. Ann ICRP 37(2-4):1-332

6. The International Commission on Radiological Protection (2007) Radiation protection in medicine. ICRP Publication 105. Ann ICRP 37(6):1-64

7. The Royal College of Radiologists (2007) Making the best use of clinical radiology services, 6th ed., London

8. European Commission (2007) Referral Guidelines for imaging, Luxembourg. Available via http://ec.europa.eu/energy/nuclear/ radioprotection/publication/doc/118_update_en.pdf. Accessed 12 Oct 2009

9. American College of Radiology. ACR Appropriateness Criteria. Available via http://www.acr.org/SecondaryMainMenuCategories/ quality_safety/app_criteria.aspx. Accessed 30 Sept 2009

10. Thomas KE, Parnell-Parmley JE, Haidar S, Moineddin R, Charkot E, BenDavid G, Krajewski C (2006) Assessment of radiation dose awareness among pediatricians. Pediatr Radiol 36:823-832

11. Soye JA, Paterson A (2008) A survey of awareness of radiation dose among health professionals in Northern Ireland. Br J Radiol 81:725-729

12. Shiralkar S, Rennie A, Snow M, Galland RB, Lewis MH, GowerThomas K (2003) Doctors' knowledge of radiation exposure: questionnaire study. BMJ 327:371-372

13. Rice HE, Frush DP, Harker MJ, Farmer D, Waldhausen JH (2007) Peer assessment of pediatric surgeons for potential risks of radiation exposure from computed tomography scans. J Pediatr Surg 42:1157-1164 
14. Renston JP, Connors AF Jr, DiMarco AF (1996) Survey of physicians' attitudes about risks and benefits of chest computed tomography. South Med J 89:1067-1073

15. Quinn AD, Taylor CG, Sabharwal T, Sikdar T (1997) Radiation protection awareness in non-radiologists. Br J Radiol 70:102-106

16. Lee CI, Haims AH, Monico EP, Brink JA, Forman HP (2004) Diagnostic CT scans: assessment of patient, physician, and radiologist awareness of radiation dose and possible risks. Radiology 231:393-398

17. Jacob K, Vivian G, Steel JR (2004) X-ray dose training: are we exposed to enough? Clin Radiol 59:928-934

18. Heyer CM, Peters S, Lemburg S, Nicolas V (2007) Awareness of radiation exposure of thoracic $\mathrm{CT}$ scans and conventional radiographs: what do non-radiologists know? Rofo 179:261-267

19. Gumus Cesur (2009) Turkish pediatric surgeons knowledge on radiation exposure of patients during diagnostic imaging. Turkie Klinikerie J Med Sci

20. Finestone A, Schlesinger T, Amir H, Richter E, Milgrom C (2003) Do physicians correctly estimate radiation risks from medical imaging? Arch Environ Health 58:59-61

21. Correia MJ, Hellies A, Andreassi MG, Ghelarducci B, Picano E (2005) Lack of radiological awareness among physicians working in a tertiary-care cardiological centre. Int J Cardiol 103:307-311

22. Arslanoglu A, Bilgin S, Kubal Z, Ceyhan MN, Ilhan MN, Maral I (2007) Doctors' and intern doctors' knowledge about patients' ionizing radiation exposure doses during common radiological examinations. Diagn Interv Radiol 13:53-55

23. Mankad K, Bull M (2005) Awareness of 'Making the best use of a Department of Clinical Radiology' amongst physicians. Clin Radiol 60:618-619

24. Bautista AB, Burgos A, Nickel BJ, Yoon JJ, Tilara AA, Amorosa JK (2009) Do clinicians use the American College of radiology appropriateness criteria in the management of their patients? AJR Am J Roentgenol 192:1581-1585

25. Newton J, Knight D, Woolhead G (1996) General practitioners and clinical guidelines: a survey of knowledge, use and beliefs. $\mathrm{Br}$ J Gen Pract 46:513-517

26. Tunis SR, Hayward RS, Wilson MC, Rubin HR, Bass EB, Johnston M, Steinberg EP (1994) Internists' attitudes about clinical practice guidelines. Ann Intern Med 120:956-963

27. Ammendolia C, Bombardier C, Hogg-Johnson S, Glazier R (2002) Views on radiography use for patients with acute low back pain among chiropractors in an Ontario community. J Manipulative Physiol Ther 25:511-520

28. Ammendolia C, Cote P, Hogg-Johnson S, Bombardier C (2007) Do chiropractors adhere to guidelines for back radiographs? A study of chiropractic teaching clinics in Canada. Spine (Phila Pa 1976) 32:2509-2514

29. Act of 28. Feb 1997 no. 19 National Insurance Act. Ministry of Health and Social Affairs, Oslo. Available via http://www.lovdata. no/all/nl-19970228-019.html. Accessed 12 Oct 2009

30. Friberg EG, Widmark A, Olerud HM, Tynes, Saxebøl, G (2005) Guidance for use of medical X-ray and MR equipment subjected to approval. Guidance to "Regulations for radiation protection and use of radiation". Guidance No.5. In Norwegian. Norwegian Radiation Protection Authority, Østerås

31. Norwegian Radiation Protection Authority Web site. Available via http://www.nrpa.no/index.asp? Accessed 1 Oct 2009

32. Norwegian Medical Association Web site. Available via http:// www.legeforeningen.no/id/146323. Accessed 12 Oct 2009

33. Ratnapalan S, Bona N, Chandra K, Koren G (2004) Physicians' perceptions of teratogenic risk associated with radiography and CT during early pregnancy. AJR Am J Roentgenol 182:1107-1109

34. Kumar S, Mankad K, Bhartia B (2007) Awareness of making the best use of a Department of Clinical Radiology amongst physicians in Leeds Teaching Hospitals, UK. Br J Radiol 80:140

35. Norwegian Radiology Society Web site. Available via http://www. radiologforeningen.no/external/guidelines/INDEX.html. Accessed 12 Oct 2009

36. Manuellterapeutenes servicekontor (2007) Retningslinjer for bildediagnostisk utredning (Guidelines for diagnostic imaging workup). In Norwegian. Available via http://www.manuellterapi. no/dokumenter/RL_bildediagnostisk_utredning_20070000.pdf Accessed 12 Oct 2009

37. Royal College of Radiologists Working Party (1992) A multicentre audit of hospital referral for radiological investigation in England and Wales. World Hosp 28:7-13

38. Royal College of Radiologists Working Party (1992) Influence of the Royal College of Radiologists' guidelines on hospital practice: a multicentre study. BMJ 304:740-743

39. Almén A, Leitz W, Richter S. (2009) National Survey on Justification of CT-examinations in Sweden. 2009:3. Swedish Radiation Safety Authority.

40. Matowe L, Ramsay CR, Grimshaw JM, Gilbert FJ, Macleod MJ, Needham G (2002) Effects of mailed dissemination of the Royal College of Radiologists' guidelines on general practitioner referrals for radiography: a time series analysis. Clin Radiol 57:575-578

41. Remedios D, McCoubrie P, The Royal College Of Radiologists Guidelines Working Party (2007) Making the best use of clinical radiology services: a new approach to referral guidelines. Clin Radiol 62:919-920

42. Grimshaw JM, Winkens RA, Shirran L, Cunningham C, Mayhew A, Thomas R, Fraser C (2005) Interventions to improve outpatient referrals from primary care to secondary care. Cochrane Database Syst RevCD005471

43. Mendelson RM, Murray CP (2007) Towards the appropriate use of diagnostic imaging. Med J Aust 187:5-6

44. Sistrom CL (2005) The ACR appropriateness criteria: translation to practice and research. J Am Coll Radiol 2:61-67

45. Amis ES Jr, Butler PF, Applegate KE, Birnbaum SB, Brateman LF, Hevezi JM, Mettler FA, Morin RL, Pentecost MJ, Smith GG, Strauss KJ, Zeman RK (2007) American College of Radiology white paper on radiation dose in medicine. J Am Coll Radiol 4:272-284

46. Prevedello LM, Sodickson AD, Andriole KP, Khorasani R (2009) IT tools will be critical in helping reduce radiation exposure from medical imaging. J Am Coll Radiol 6:125-126 